\title{
Impacto da Campanha Olho no Olho em escolas de ensino fundamental - Percepção do pessoal de ensino
}

\author{
Effectiveness of visual screening in elementary schools - Educators'perception
}

\author{
Heloisa Helena Abil Russ ${ }^{1}$ \\ Edméa Rita Temporini ${ }^{2}$ \\ Newton Kara-José ${ }^{3}$
}

\section{RESUMO}

Objetivos: 1) Identificar conhecimentos do pessoal de ensino anteriores ao treinamento da Campanha Olho no Olho. 2) Identificar percepção da qualidade do treinamento. 3) Identificar percepção sobre os benefícios e adesão à campanha. Métodos: Estudo analítico transversal. Escolas municipais de Curitiba-PR. Aplicação de questionário auto-aplicável. Resultados: Foram entrevistados $89 \%$ dos participantes e destes apenas $13 \%$ eram professores regentes. $\mathrm{O}$ treinamento global foi considerado bom por $85,9 \%$. Dos professores todos tinham mais de 10 anos de magistério. Os professores consideraram importante obter em futuro treinamento melhores orientações sobre como controlar o caso de aluno encaminhado que necessite de tratamento $(59,3 \%)$. Das crianças triadas, 94,2\% foram atendidas e $84,9 \%$ dos óculos foram entregues. Dos alunos que tiveram prescrição de óculos, $85,7 \%$ obtiveram melhora do desempenho escolar. O agente de saúde $(36,1 \%)$ e o médico oftalmologista $(29,7 \%)$ foram citados como responsáveis pela triagem; apenas $0,9 \%$ acham que a triagem compete ao professor. Cerca de $50,5 \%$ dos pais apresentaram interesse pelas atividades da campanha, e a maior justificativa para abstenções foi impossibilidade de faltar ao trabalho $(68,5 \%)$ e desconhecimento da dificuldade visual do filho $(50,0 \%)$. Conclusões: 1$)$ Os professores do estudo apresentavam conhecimento satisfatório sobre triagem visual. 2) O treinamento produzido pela Campanha Olho no Olho foi considerado bom, ressaltando-se a necessidade de incluir explicações adicionais. 3) Houve melhora do desempenho do educando, a adesão dos pais à Campanha foi boa e o número de crianças atendidas excelente.

Descritores: Triagem de massa; Erros de refração/diagnóstico; Saúde escolar; Serviços de saúde escolar; Capacitação em serviço; Ensino

Trabalho realizado nas escolas da rede municipal de ensino da cidade de Curitiba-PR

Universidade Estadual de Campinas - UNICAMP Disciplina de Oftalmologia - Campinas (SP) CEP 13084-970

${ }^{1}$ Mestre em Oftalmologia pela Universidade Estadual de Campinas - UNICAMP.

${ }^{2}$ Professora Livre-Docente pela Faculdade de Saúde Pública da Universidade de São Paulo - USP.

${ }^{3}$ Professor Titular da Clínica Oftalmológica da Universidade de São Paulo - USP e da Universidade Estadual de Campinas - UNICAMP

Endereço para correspondência: Rua Professora Rosa Saporski, 690 - Curitiba (PR) CEP 80810-120

E-mail: heloisaruss@ netpar.com.br

Recebido para publicação em 28.03.2003

Versão revisada recebida em 17.09.2003

Aprovação em 12.11.2003

Nota Editorial: Pela análise deste trabalho e por sua anuência na divulgação desta nota, agradecemos ao Dr. Cláudio do Carmo Chaves.

\section{INTRODUÇ̃̃̃O}

A cegueira é a mais custosa de todas as formas de invalidez ${ }^{(1)}$. Segundo dados da Organização Mundial da Saúde (OMS), existem cerca de 38 milhões de pessoas cegas no mundo e 110 milhões apresentando visão deficiente e risco acentuado de se tornarem cegas, das quais dois terços dos casos seriam potencialmente evitáveis ou curáveis. Esta situação torna-se mais grave nos países em desenvolvimento onde se localizam $80 \%$ dos casos de cegueira ${ }^{(2)}$.

A cegueira na infância torna-se particularmente importante em países como o Brasil devido aos elevados índices de incidência bem como pelo encargo socioeconômico que representa ${ }^{(3-4)}$. Burns cita que "a sociedade paga um preço muito alto pelo cuidado inadequado da visão. As conseqüências da visão deficiente, não tratada, afetam o comportamento social, 
causam acidentes de trabalho e roubam a confiança e independência dos mais velhos"(5). Estima-se que 80 a $85 \%$ do processo ensino-aprendizagem dependa da visão. Além disso, o desenvolvimento psicossocial do ser humano pode também ser afetado por distúrbios visuais não identificados e tratados precocemente $^{(5)}$.

Nos Estados Unidos, $60 \%$ da população adulta usa correção óptica e cerca de $25 \%$ das crianças em idade escolar apresenta algum tipo de problema ocular, como os erros refracionais (miopia, astigmatismo e hipermetropia), ambliopia e estrabismo $^{(5-8)}$.

No Brasil, estima-se que a prevalência de ambliopia em crianças de 4 a 6 anos de idade é 2,8\%, segundo estudo realizado por Kara-José et al na Universidade Estadual de Campinas, tendo como principal causa ambliopia refracional ${ }^{(3,9)}$. Tendo por base essa percentagem, estima-se que existam cerca de 4,5 milhões de indivíduos com deficiência visual potencialmente curável em nosso país. Em outras palavras, programas efetivos de detecção precoce de distúrbios visuais são incomparavelmente menos dispendiosos do que representam para a comunidade os portadores de cegueira ${ }^{(5,10-13)}$.

De acordo com os princípios gerais de triagem ou 'screening”, a detecção precoce de distúrbios visuais na infância é viável, pois constitui problema de saúde pública, tem diagnóstico confiável e o tratamento efetivo é possível na maioria dos $\operatorname{casos}^{(14-18)}$.

Segundo a OMS, a acuidade visual é o indicador mais sensível da função visual, sendo o teste simples, confiável, de baixo custo, alta sensibilidade e especificidade ${ }^{(13,19-20)}$, além de não requerer treinamento prolongado dos examinadores ${ }^{(17)}$.

O Baltimore Vision Screening Project ${ }^{(15-16)}$ relata que cerca de dois terços das crianças examinadas não aderiram ao tratamento proposto (óculos e/ou oclusão), a despeito do acesso aos óculos ter sido fornecido pelo projeto de imediato. Os pais ou responsáveis desconheciam o resultado do exame ou não entendiam a importância do tratamento proposto.

No Brasil, desde a década de 70 existem programas de triagem realizados nas escolas públicas com posterior encaminhamento a serviços oftalmológicos, como o Plano de Oftalmologia Sanitária Escolar (POSE) no Estado de São Paulo, criado em $1973^{(4)}$ e extinto em 1976 devido a mudanças de cunho político. Na década de 90 houve a criação da Campanha Nacional de Reabilitação Visual - Projeto Olho no Olho/"Veja Bem Brasil" em 1998, uma parceria do Conselho Brasileiro de Oftalmologia e do Ministério da Educação/FNDE, instituindo a triagem de todas as crianças da primeira série de ensino fundamental em todas as cidades com população superior a 40 mil habitantes. No ano de 1999, o Programa atendeu 2 milhões e 280 mil crianças, fornecendo gratuitamente 256.815 óculos. No ano de 2000, fez 450.000 consultas e forneceu 300.000 óculos $^{(18)}$.

Em campanhas anteriores, detectou-se que a causa da ambliopia em $87,65 \%$ dos examinados era funcional e não orgânica ${ }^{(1)}$, portanto passível de tratamento com correção óptica, e destes, apenas 19,9\% tinham sido submetidos à avaliação ocular prévia.
A concordância entre a triagem realizada pelo professor e pelo médico varia de $54,6 \%$ a $80,86 \%{ }^{(5,20-21)}$, confirmando que treinamento de agentes de saúde para realização da triagem e encaminhamento deve ser periódico.

A eficácia do "Screening" depende do índice de comparecimento, que tem variado de $57 \%$ a $95 \%{ }^{(1,22-23)}$. Pode-se sugerir que as abstenções ocorrem porque o problema não é aparente e muitas vezes o amblíope não tem consciência de sua condição, levando à conseqüente desmotivação dos pais ${ }^{(20,24-25)}$.

No Brasil, a triagem visual vem sendo realizada pelos professores das escolas públicas e em alunos da primeira série de ensino fundamental desde 1998.

O contato diário e prolongado com alunos favorece a observação do estado de saúde e o desempenho visual e intelectual dos escolares pelo professor ${ }^{(26-27)}$. No entanto, o professor nem sempre dispõe de conhecimentos, atitudes, habilidades e práticas no campo da saúde ocular. Há ainda grande descontentamento por partes dos professores responsáveis pela triagem, que aparentemente se acham despreparados para realizar tal tarefa ${ }^{(28)}$.

Pode-se inferir que há benefícios decorrentes dos resultados da campanha, o que suscitou a realização da pesquisa. A qualidade do treinamento destinado aos professores igualmente não foi mensurada.

\section{OBJETIVOS}

1. Identificar conhecimentos do pessoal de ensino adquirido previamente ao treinamento do Programa Nacional de Reabilitação Visual "Veja bem Brasil" em relação aos critérios de encaminhamento e identificação de dificuldades visuais de escolares na triagem.

2. Identificar a percepção do pessoal de ensino em relação à qualidade do treinamento do Programa Nacional de Reabilitação Visual "Veja bem Brasil".

3. Identificar percepção de professores em relação aos benefícios no rendimento escolar de alunos e adesão à campanha por pais e alunos.

\section{MÉTODOS}

\section{1)Tipo de Pesquisa}

Survey analítico transversal realizado nas escolas da rede municipal da cidade de Curitiba-Paraná.

\section{2) População}

a) Profissionais atuantes na rede municipal de ensino da Prefeitura de Curitiba-PR (professores, diretores, coordenadores e funcionários administrativos) que participaram do treinamento ministrado pela Secretaria de Educação no ano de 2000 e que realizaram o teste de acuidade visual nos alunos da primeira série de ensino fundamental. 
b) Escolas públicas municipais (127 escolas) selecionadas a partir dos profissionais que participaram do treinamento ministrado pela Secretaria de Educação no ano de 2000.

\section{3) Variáveis}

a) Características profissionais e opinião dos professores com relação a:

conhecimento sobre aplicação de teste de acuidade visual, critérios de encaminhamento, sinais, sintomas e comportamentos indicativos de problemas oculares.

preparação de professores sobre saúde ocular:

- tipo de treinamento recebido: conteúdo, carga horária, responsável pela orientação, tipo de atividade (material, quantidade e qualidade das intervenções educativas), dramatização do teste de acuidade visual.

Opinião dos professores em relação à:

- necessidade da triagem visual na escola

- a quem cabe a triagem na escola

- época da triagem visual na escola

- colaboração dos pais

- desempenho da criança

b) Características profissionais e opinião do pessoal de ensino com relação aos mesmos critérios anteriores. (Vide questionário)

\section{4) Instrumento}

Para elaboração dos instrumentos de medida foi utilizado o recurso da pesquisa exploratória como etapa preliminar, para adequar esses instrumentos à realidade estudada. O questionário contendo questões estruturadas era auto-aplicável.

\section{5) Análise estatística}

Além do valor escalar médio (VEM), tratamento matemático que reduz dados de uma distribuição a um único valor, recorreu-se à análise descritivas dos dados através de tabelas e gráficos. Foram utilizados os testes não paramétricos "comparação entre duas proporções", Qui-Quadrado e Exato de Fischer com nível de significância menor que 5\% $(\mathrm{p}<0,05)$.

\section{RESULTADOS}

Foram entrevistados 113 dos 127 (89\%) participantes do treinamento da Campanha Olho no Olho na cidade de Curitiba no ano de 2000. As entrevistas foram realizadas no período de março a novembro de 2001.

A amostra foi formada por pedagogos $(33,6 \%)$, orientadoras educacionais $(21,3 \%)$ e auxiliar de serviços escolares $(15,7 \%)$ e diretores $(9,3 \%)$. Apenas $13 \%$ dos participantes eram professores-regentes.

Quanto à carga horária semanal, 49,5\% perfaziam 40 horas semanais. Quanto ao ter po de exercício profissional, $43,0 \%$ do pessoal de ensino tinham no máximo 10 anos de carreira enquanto dentre os professores 100,0\% tinham mais de 10 anos de magistério. Com relação à satisfação, 44,2\% se diziam muito satisfeitos com a profissão, apenas 3,2\% dos respondentes se intitularam insatisfeitos com a atividade que exercem.

O conteúdo teórico do Programa Olho no Olho foi considerado "bom" por $66,4 \%$, bem como o conteúdo prático por $68,1 \%$. A carga horária pré-estabelecida foi considerada "boa" por $64,6 \%$ dos entrevistados.

Em relação ao material didático, o manual de orientação aos professores foi considerado por $56,6 \%(\mathrm{VEM}=4,1)$ dos entrevistados como "bom", bem como os Manuais Educativos $(51,3 \%$ e VEM $=4,3)$ e o vídeo $(58,4 \%$ e VEM $=4,2)$.

O treinamento global foi considerado "bom" e/ou "ótimo" por $85,9 \%$ dos respondentes (VEM $=4,1)$.

A orientação fornecida pelos médicos oftalmologistas foi considerada "boa" $(56,6 \%)$, assim como a orientação ministrada por outro profissional $(57,5 \%)$.

A aplicação do teste de acuidade visual, o reconhecimento de sinais de dificuldade visual e razões para encaminhamento oftalmológico já era conhecido por 56,5\%; 64,5\% e 66,7\%, respectivamente, bem como orientação dos pais sobre as dificuldades visuais do aluno (64,4\%). Porém, a notação de dados referentes à triagem visual e o controle do caso do aluno foram aprendidos durante o treinamento por $61,5 \%$ e $35,7 \%$, respectivamente.

Os professores consideraram importante obter em futuro treinamento melhores orientações sobre como controlar o caso de um aluno encaminhado para consulta e que necessite de tratamento $(59,3 \%)$. Os demais aspectos foram considerados suficientes: orientação da família do aluno com dificuldade visual $(58,4 \%)$; orientação do aluno encaminhado $(72,6 \%)$; aplicação do teste de acuidade visual $(78,8 \%)$, como fazer observação de sinais indicativos de dificuldade visual $(62,8 \%)$, critérios de encaminhamento $(61,9 \%)$, notação de dados referentes à triagem $(77,9 \%)$.

Dos respondentes, $87,3 \%$ opinaram que a triagem deveria ser realizada no primeiro trimestre do ano letivo, e $96,4 \%$ consideraram a triagem muito importante.

O agente de saúde $(36,1 \%)$ e o médico oftalmologista (29,7\%); foram citados como responsáveis pela triagem pelos entrevistados; apenas $0,9 \%$ acham que a triagem compete ao professor (Tabela 1). As dificuldades apontadas para a realização do programa estão demonstradas na tabela $2 \mathrm{em}$ forma de associação.

Cerca de 50,5\% dos pais apresentaram interesse pelas atividades da campanha, segundo relato dos respondentes.

Dentre as dificuldades apontadas pelos pais, podemos citar: desconhecimento da dificuldade visual do filho $(50,0 \%)$; falta de dinheiro $(44,2 \%)$; falta de transporte $(11,6 \%)$; impossibilidade de faltar ao trabalho $(68,5 \%)$; desconhecimento da data da consulta oftalmológica $(11,1 \%)$.

Em relação ao aluno que usa óculos, 100,0\% acham que o professor deve cobrar o uso dos mesmos pelo aluno, estimulálo $(92,9 \%)$; explicar para a classe o que significa o uso de óculos (100,0\%); e é considerado importante por 50,0\% a observação 


\begin{tabular}{|c|c|c|c|c|c|c|}
\hline \multirow[t]{2}{*}{ Profissional responsável } & \multicolumn{2}{|c|}{$\begin{array}{c}\text { Professores } \\
(N=14)\end{array}$} & \multicolumn{2}{|c|}{$\begin{array}{l}\text { Outros } \\
(\mathrm{N}=99)\end{array}$} & \multicolumn{2}{|c|}{$\begin{array}{c}\text { Total } \\
(n=113)\end{array}$} \\
\hline & $\mathrm{N}^{\circ}$ & $\%$ & $\mathrm{~N}^{\circ}$ & $\%$ & $\mathrm{~N}^{\circ}$ & $\%$ \\
\hline Resposta & 14 & 100,0 & 94 & 94,9 & 108 & 95,6 \\
\hline Professor & - & - & 1 & 1,1 & 1 & $0, \subseteq$ \\
\hline Agente de saúde (AS) & 3 & 21,4 & 36 & 38,3 & 39 & 36,1 \\
\hline Outro funcionário (OF) & 3 & 21,4 & 7 & 7,4 & 10 & 9,3 \\
\hline Médico oftalmologista & 5 & 35,7 & 27 & 28,7 & 32 & 29,7 \\
\hline Professor + Médico & 1 & 7,2 & - & - & 1 & $0, c$ \\
\hline Agente saúde + Outro funcionário & - & - & 3 & 3,2 & 3 & 2,8 \\
\hline Agente saúde + Médico & 2 & 14,3 & 18 & 19,1 & 20 & 18,5 \\
\hline Outro funcionário + Médico & - & - & 1 & 1,1 & 1 & $0, \subseteq$ \\
\hline Agente saúde + Outro + Médico & - & - & 1 & 1,1 & 1 & $0, \subseteq$ \\
\hline \multicolumn{7}{|c|}{ Número $\rightarrow \chi_{\text {calc }}^{2}=4,72$ e $p=0,1933 ;$ Resposta $\rightarrow \chi_{\text {calc }}^{2}=3,90$ e $p=0,4197$ (Qui-Quadrado); Tipo $\rightarrow p=0,5520$ (Fisher) } \\
\hline
\end{tabular}

\begin{tabular}{|c|c|c|c|c|c|c|c|c|}
\hline \multicolumn{2}{|c|}{ Respondentes } & \multirow{2}{*}{$\begin{array}{l}\text { O cronograma } \\
\text { de atendimento } \\
\text { foi curto }\end{array}$} & \multirow{2}{*}{$\begin{array}{l}\text { Dificuldade de } \\
\text { deslocamento } \\
\text { do professor da } \\
\text { sala de aula }\end{array}$} & \multirow{2}{*}{$\begin{array}{l}\text { Falta de confiança } \\
\text { dos pais no exame }\end{array}$} & \multirow{2}{*}{$\begin{array}{c}\text { Desconhecimento } \\
\text { dos pais sobre } \\
\text { a dificuldade } \\
\text { visual do filho }\end{array}$} & \multirow{2}{*}{$\begin{array}{l}\text { Distância do } \\
\text { local de exame }\end{array}$} & \multirow[t]{2}{*}{ Outra } & \multirow[t]{2}{*}{ razão } \\
\hline$f$ & $\%$ & & & & & & & \\
\hline 8 & 11,4 & & & & & 8 & & \\
\hline 8 & 11,4 & & & & & & & 8 \\
\hline 8 & 11,4 & 8 & & & & & & \\
\hline 7 & 10,0 & & 7 & & & & & \\
\hline 6 & 8,6 & 6 & & & & 6 & & \\
\hline 6 & 8,6 & & & & 6 & & & \\
\hline 4 & 5,7 & & & & 4 & 4 & & \\
\hline 4 & 5,7 & 4 & 4 & & & & & \\
\hline 4 & 5,7 & & 4 & & 4 & & & \\
\hline 3 & 4,3 & 3 & & & & & & 3 \\
\hline 3 & 4,3 & 3 & 3 & & 3 & & & \\
\hline 3 & 4,3 & 3 & 3 & & & 3 & & \\
\hline 3 & 4,3 & & 3 & & & 3 & & \\
\hline 3 & 4,3 & & & & & 3 & & 3 \\
\hline 70 & 100,0 & & & & & & & \\
\hline${ }^{*}$ For & m excluíc & s respostas asso & as fornecidas $p c$ & ou menos respor & & & & \\
\hline
\end{tabular}

da limpeza das lentes. Porém 35,7\% não acham que o professor deve aceitar comportamentos inerentes à dificuldade visual.

Segundo dados dos professores, das crianças triadas, $94,2 \%$ foram atendidas e $84,9 \%$ dos óculos foram entregues.

Os entrevistados consideraram a participação da escola "ótima" $(39,3 \%)$ e 50,0\% consideraram "boa".

Dos alunos usuários de óculos, 50,0\% usam em classe. $\mathrm{Na}$ opinião desses professores, dos alunos que tiveram prescrição de óculos e os usaram, 85,7\% obtiveram melhora do desempenho escolar.

Dentre as sugestões citadas pelos profissionais estão: realização do exame oftalmológico na escola ou na unidade de saúde, aplicação do teste de acuidade visual por profissional da área de saúde, além da ampliação e antecipação das atividades da campanha.

\section{DISCUSSÃO}

Cerca de $85 \%$ do contato do homem com o mundo se faz por meio da visão ${ }^{(5)}$ sendo que um déficit representa prejuízo para aprendizado e socialização da criança. A escola, por meio do professor,tem tido o importante papel de detectar as dificuldades visuais apresentadas pelos educandos ${ }^{(9)}$.

O contato diário e prolongado com alunos favorece a observação do estado de saúde e o desempenho visual e intelectual dos escolares pelo professor ${ }^{(28)}$. No entanto, o professor nem sempre dispõe de conhecimentos, atitudes, habilidades e práticas no campo da saúde ocular.

A Campanha "Veja bem Brasil", desenvolvida pelo Conselho Brasileiro de Oftalmologia em conjunto com o Ministério 
da Educação desde 1998, tem obtido bons resultados, e, segundo os respondentes, resultou em melhora do rendimento escolar.

Porém, apesar dessa relativa facilidade de detecção de alterações visuais pelo professor, apenas $13,0 \%$ dos profissionais que participaram do treinamento eram professores regentes. A maior parte do grupo foi formado por diretores, pedagogos, orientadores educacionais e auxiliares administrativos, que tem um contato pequeno com a classe. A dificuldade de deslocar o professor da sala de aula seja para o treinamento ou para aplicação do teste de acuidade visual, foi apontada como uma dificuldade encontrada na realização da campanha.

Além disso, apesar da maioria dos professores considerar a triagem muito importante, proporção ínfima acham que a triagem compete ao professor. Os demais concordam que a aplicação do teste deve-se a profissionais da área da saúde, para maior reprodutibilidade. Segundo Kara-José e Tempori$\mathrm{ni}^{(20)}$ a triagem é realizada corretamente pelo professor treinado em $87,1 \%$ dos casos.

Outra queixa freqüente é o período ideal para realização do exame: $87,20 \%$ concordam que o primeiro trimestre letivo é o período ideal, associado a uma extensão do cronograma, visto que a mudança do calendário possibilitaria melhor seguimento dos alunos.

A Campanha teve seus objetivos alcançados pela demonstração dos números de adesão: quase a totalidade das crianças triadas foram atendidas e a maioria dos óculos foi entregue. Dos alunos que tiveram óculos prescritos, houve melhora do rendimento escolar compatível com dados da literatura(15-16).

Houve interesse de número significativo dos pais pelas atividades da campanha, diferente dos dados apresentados pelo Baltimore Vision Screening Project ${ }^{(15-16)}$. A impossibilidade de faltar ao trabalho foi o fator responsável pela maioria das abstenções, além do desconhecimento da dificuldade visual do filho.

Faz-se necessário a sensibilização dos professores, pois em sala de aula contam com situação ímpar em relação à observação das dificuldades visuais e queixas destes alunos nas atividades escolares. $\mathrm{O}$ aluno nem sempre consegue verbalizar as dificuldades visuais, por isso o professor deve ficar atento para possíveis manifestações como dificuldade de locomoção, ler, copiar, etc ${ }^{(10)}$.

A escola pode e deve participar de ações de promoção da saúde ocular, de identificação e encaminhamento de alunos a especialistas. Porém o professor deve ser capacitado para poder realizar as atividades de prevenção à cegueira ${ }^{(4,22,28)}$.

Quanto ao treinamento do programa, considerado bom pelos professores, deve ser melhorado e aprofundado ano a ano, a fim de que não seja repetitivo e para que a parceria entre escola, professores e oftalmologistas possa ser concretizada e novos frutos sejam colhidos.

\section{CONCLUSÕES}

1. Os professores do estudo apresentavam conhecimento satisfatório sobre triagem visual e saúde ocular, porém não se manifestaram suficientemente seguros para realização da Campanha Olho no Olho.

2. O treinamento produzido pela Campanha Olho no Olho foi considerado bom, ressaltando-se a necessidade de incluir explicações sobre como conduzir e acompanhar casos de alunos com deficiência visual. A triagem visual foi reconhecida como muito importante, porém não como atribuição do professor.

3. A maioria dos profissionais reconheceu que a triagem por eles realizada tem obtido bons resultados, melhorando o desempenho do educando. Na opinião do pessoal de ensino a adesão dos pais à Campanha foi boa e o número de crianças encaminhadas e atendidas excelente.

\section{SUGESTÕES}

- Faz-se necessário o reforço e padronização do treinamento.

- Criar medidas de incentivo e sensibilização dos professores.

- Realização periódica de pesquisas que avaliem o treinamento e as atividades realizadas de saúde ocular.

- Divulgação ampla da campanha nos meios de comunicação a fim de estimular alunos, professores e familiares.

\section{ABSTRACT}

Purposes: To identify knowledge of educators before visual screening training. 2) To identify educator perceptions about quality of training. 3) To identify benefits and compliance with the campaign. Methods: Analytical transversal survey. Public schools of Curitiba-PR. Self-application of questionnaire. Results: Of the $89 \%$ interviewed people, only $13 \%$ were school teachers. The global training was considered good by $85.9 \%$. All teachers had more than 10 years of teaching activities. The teachers asked for more information in a future training about how to manage children whose treatment was necessary (59.3\%). Of the screened children, $94.2 \%$ were seen by the doctors and $84.9 \%$ had prescriptions for spectacles. Of these, $85.7 \%$ improved their learning performance. The health agent $(36.1 \%)$ and the ophthalmologist (29.7\%) were taught to be responsible for the visual screening; only $0.9 \%$ considered this a teacher's duty. About $50.5 \%$ of parents participated in the activities of the campaign, and the majority justified abstention due to their work $(68.5 \%)$ besides the lack of knowledge about visual difficulties of their children (50\%). Conclusions: 1) The educators had a satisfactory knowledge about visual screening. 2) Visual training was considered good, but additional information is necessary. 3) There were improvement of learning, parents' compliance was good and the number of children seen by doctors was excellent.

Keywords: Mass screening; Refractive errors/diagnosis; School health; School health services; Inservice training; Teaching 


\section{Questionário $\mathrm{n}^{\circ} 1$}

1) Em 2001, quantos anos você completa de magistério? anos

2) Qual é a sua carga horária semanal como professor?

20 horas

30 horas

40 horas

mais de 40 horas

3) Você leciona em uma escola apenas, ou em mais de uma escola?

Leciono em apenas uma escola.....

Leciono em duas escolas

Leciono em mais de duas escolas

4) Qual o seu grau de satisfação em relação ao desempenho da sua atividade docente?

Muito satisfeito(a)

Medianamente satisfeito(a)

Pouco satisfeito(a)

Nada satisfeito(a)

5) Avalie o último treinamento sobre as atividades da campanha "Olho no Olho" de que você participou. Assinale sua opinião referente a cada item abaixo mencionado.

I. Conteúdo teórico

II. Conteúdo prático

III. Carga horária

IV. Manual de orientação de professores

V. Manuais educativos (Boa Visão)

VI. Vídeo

VII. Orientação dada por oftalmologista

VIII. Orientação dada por outros profissionais

Ótimo(5)

Bom (4)

Regular (3)

Ruim (2)

Péssimo (1)

6) De modo geral, na sua opinião esse treinamento foi:

- Ótimo
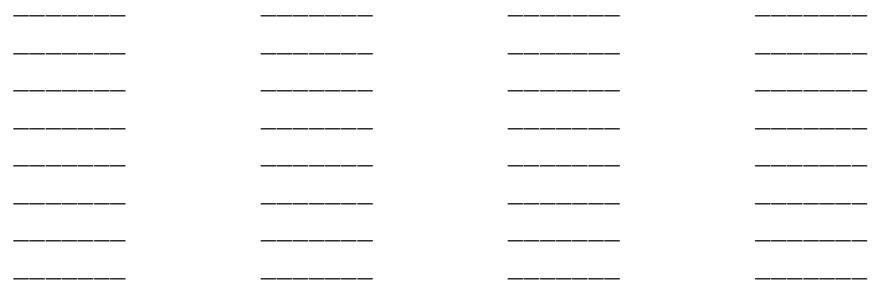

- Bom

- Regular

(2)

(3)

- Ruim

Péssimo

Não tenho opinião

7) Assinale o que você aprendeu no último treinamento e o que você já sabia antes: (RESPONDA A TODAS S ALTERNATIVAS)

- Aplicar teste de acuidade visual visual

- Reconhecer sinais de dificuldade visual nos alunos

- Encaminhar aluno à consulta oftalmológica

- Orientar pais sobre dificuldades visuais dos alunos

- Registrar dados referentes à triagem visual que você fez

- Controle do caso de aluno com dificuldade visual (óculos, cirurgia, retorno ao médico)

Aprendeu no treinamento (1)

Sabia antes(2)

Não foi abordado(3)

8) Quem assistiu o último treinamento do qual você participou?

- Professores
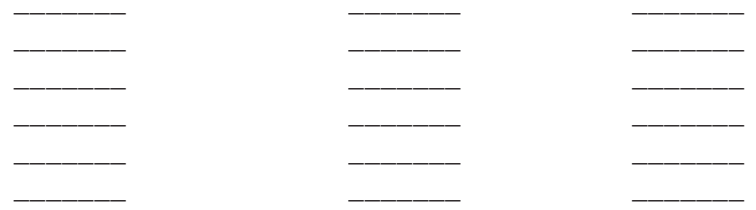

- Orientadores educacionais

(2)

- Diretores

- Supervisores

- Auxiliares de direção

9) Você acha necessário receber mais explicações sobre: (RESPONDA A TODAS AS ALTERNATIVAS)

I. A aplicação do teste de acuidade visual?

II. Como fazer a observação de sinais que indicam dificuldade visual do aluno?

III. Critério para encaminhar aluno ao oftalmologista?

IV. Como orientar o aluno para o encaminhamento ao oftalmologista?

V. Como orientar a família do aluno que tem dificuldade visual?

VI. Como registrar dados referentes à triagem visual na escola?

VII. Como controlar o caso de aluno encaminhado para consulta oftalmológica?

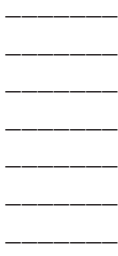


10) Na sua opinião, qual o melhor período do ano letivo para a realização da triagem visual na escola?

- No $1^{\circ}$ trimestre do ano letivo

- No $2^{\circ}$ trimestre do ano letivo

- No $3^{\circ}$ trimestre do ano letivo

- No $4^{\circ}$ trimestre do ano letivo

- Não importa o período

11) Na sua opinião, a quem caberia aplicar o teste de acuidade visual em escolares?

- Ao professor da classe

(2)

- Ao agente de saúde

- A outro funcionário da escola

- Ao médico oftalmologista

12) Na sua experiência, em relação à última triagem visual de seus alunos, dos que foram encaminhados à consulta oftalmológica:

- Todos foram atendidos

- A maioria foi atendida

- A minoria foi atendida

- Nenhum foi atendido (PASSE P/Q 15)

- Desconheço se houve atendimento (PASSE P/Q 15)

13) Você notou alguma mudança no desempenho escolar dos alunos que, após a consulta oftalmológica, passaram a usar óculos?

- Notei grande mudança...

- Notei uma mudança mediana

- Notei pequena mudança

- Notei que não houve mudança

14) Dos alunos que receberam óculos, eles costumam usá-los na classe?

- Todos os que tem óculos, usam

- Nem todos que tem óculos, usam

- Nenhum destes alunos está usando os óculos

15) Houve dificuldades para a realização do exame oftalmológico das crianças? Qual(is)? (UMA OU MAIS RESPOSTAS) Sim:

- O cronograma de atendimento foi curto

- É difícil deslocar o professor sem atrapalhar o andamento da escola

Falta de confiança dos pais no exame

- Desconhecimento dos pais sobre a dificuldade visual do filho

- Distância do local do exame

- Outra razão

- Não houve dificuldades

16) Os pais mostraram interesse sobre as atividades da campanha?

- Sim, muitos pais

- Sim, cerca de $50 \%$ dos pais

- Sim, poucos pais

- Não, nenhum

17) Quais foram as dificuldades apontadas pelos pais para os filhos não terem sido atendidos na Campanha?

- Desconhecimento sobre a dificuldade visual do filho

- Falta de dinheiro

- Falta de transporte

- Impossibilidade de faltar ao trabalho

- Desconhecimento da data da consulta oftalmológica
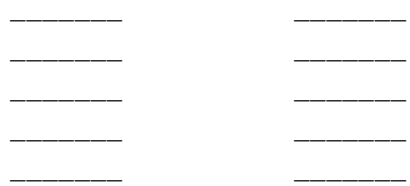

18) Na sua opinião, o que deve fazer o professor em relação ao aluno que usa óculos?

- Verificar se está usando os óculos

- Estimulá-lo a usar os óculos

- Explicar para a classe o que significa o uso de óculos

- Observar a limpeza das lentes

- Ensinar a limpar os óculos 
19) $\mathrm{Em}$ relação à entrega dos óculos aos alunos, até o presente momento:

- Todos os óculos foram entregues

- Quase todos os óculos foram entregues

- Mais ou menos metade foi entregue

- Quase nenhum, poucos foram entregues

- Nenhum óculos foi entregue

20) Como você avalia a participação do pessoal da sua escola nas atividades da Campanha "Olho no Olho"? - Ótima

- Boa

- Regular

- Má

- Péssima

21) Assinale na lista abaixo a(s) sugestão(ões) com que você concorda para melhorar próximas campanhas: (UMA OU MAIS RESPOSTAS)

- Exame oftalmológico realizado na escola.

- Treinamento dado por pessoal não-médico

- Ampliação do tempo para realização da campanha

Exame oftalmológico realizado no posto de saúde

- Aplicação do teste de acuidade visual por profissional da área de saúde

- Antecipação do início das atividades da campanha

22) Na sua opinião, a campanha para identificar e tratar problemas visuais de escolares realizada na escola é:

- Muito importante

(1)

- Medianamente importante

- Pouco importante

- Nada importante

- Não tenho opinião

\section{Questionário $\mathrm{n}^{\circ} 2$}

1) Qual a função que exerce na escola?

2) Qual é a sua carga horária semanal?

20 horas
40 horas
mais de 40 horas

3) Há quantos anos você exerce a sua profissão? anos

4) Qual o seu grau de satisfação em relação ao desempenho da sua atividade?

Muito satisfeito(a)

Medianamente satisfeito(a)

Pouco satisfeito(a)

Nada satisfeito(a)

5) Avalie o último treinamento sobre as atividades da campanha "Olho no Olho" de que você participou. Assinale sua opinião referente a cada item abaixo mencionado.

I. Conteúdo teórico

II. Conteúdo prático

III. Carga horária

IV. Manual de orientação de professores

V. Manuais educativos (Boa Visão)

VI. Vídeo

VII. Orientação dada por oftalmologista

VIII. Orientação dada por outros profissionais

Ótimo(5)

Bom (4)

Regular (3)

Ruim (2)

Péssimo (1)
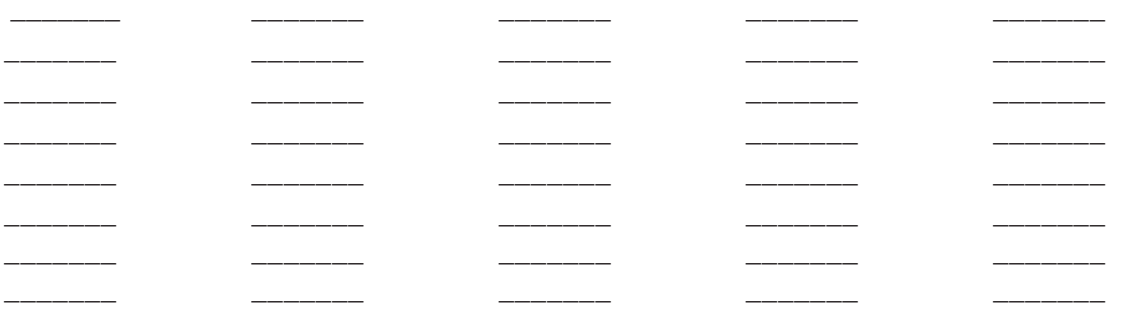
6) De modo geral, na sua opinião esse treinamento foi:

- Ótimo

- Bom.

- Regular

- Ruim

- Péssimo

- Não tenho opinião

7) Assinale o que você aprendeu no último treinamento e o que você já sabia antes: (RESPONDA A TODAS AS Aprendeu no treinamento (1) Sabia antes(2)

Aplicar teste de acuidade visual visual

- Reconhecer sinais de dificuldade visual nos alunos

- Encaminhar aluno à consulta oftalmológica

- Orientar pais sobre dificuldades visuais dos alunos

- Registrar dados referentes à triagem visual que você fez

- Controle do caso de aluno com dificuldade visual

(óculos,cirurgia, retorno ao médico)

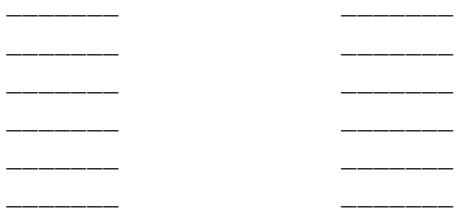

Não foi abordado(3)

8) Quem assistiu o último treinamento do qual você participou?

- Professores

(2)

- Orientadores educacionais....

- Diretores

- Supervisores

- Auxiliares de direção

(32)

9) Você acha necessário receber mais explicações sobre: (RESPONDA A TODAS AS ALTERNATIVAS)

I. A aplicação do teste de acuidade visual?

II. Como fazer a observação de sinais que indicam dificuldade visual do aluno?

III. Critério para encaminhar aluno ao oftalmologista?

IV. Como orientar o aluno para o encaminhamento ao oftalmologista?

V. Como orientar a família do aluno que tem dificuldade visual?

VI. Como registrar dados referentes à triagem visual na escola?

VII. Como controlar o caso de aluno encaminhado para consulta oftalmológica?

10) Na sua opinião, qual o melhor período do ano letivo para a realização da triagem visual na escola?

- No $1^{\circ}$ trimestre do ano letivo

- No $2^{\circ}$ trimestre do ano letivo

- No $3^{\circ}$ trimestre do ano letivo

- No $4^{\circ}$ trimestre do ano letivo

- Não importa o período

11) Na sua opinião, a quem caberia aplicar o teste de acuidade visual em escolares?

- Ao professor da classe

- Ao agente de saúde

- A outro funcionário da escola

- Ao médico oftalmologista

12) Na sua experiência, em relação à última triagem visual de seus alunos, dos que foram encaminhados à consulta oftalmológica:

- Todos foram atendidos

- A maioria foi atendida

- A minoria foi atendida

- Nenhum foi atendido (PASSE P/Q 15)

- Desconheço se houve atendimento (PASSE P/Q 15)

RESPOSTAS)

13)

- O cronograma de atendimento foi curto

- É difícil deslocar o professor sem atrapalhar o andamento da escola

- Falta de confiança dos pais no exame

- Desconhecimento dos pais sobre a dificuldade visual do filho

- Distância do local do exame

- Outra razão

- Não houve dificuldades 
14) Os pais mostraram interesse sobre as atividades da campanha?

- Sim, cerca de $50 \%$ dos pais .

(1)

- Sim, poucos pais

- Não, nenhum.

15) Quais foram as dificuldades apontadas pelos pais para os filhos não terem sido atendidos na Campanha?

- Desconhecimento sobre a dificuldade visual do filho.

- Falta de dinheiro

- Falta de transporte

- Impossibilidade de faltar ao trabalho

- Desconhecimento da data da consulta oftalmológica

16) Em relação à entrega dos óculos aos alunos, até o presente momento:

- Todos os óculos foram entregues
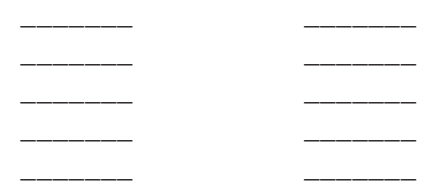

- Quase todos os óculos foram entregues

- Mais ou menos metade foi entregue

Quase nenhum, poucos foram entregues.

- Nenhum óculos foi entregue

17) Como você avalia a participação do pessoal da sua escola nas atividades da Campanha "Olho no Olho"? - Ótima

- Boa .

- Regular

- Má

- Péssima

18) Assinale na lista abaixo a(s) sugestão(ões) com que você concorda para melhorar próximas campanhas: (UMA OU MAIS RESPOSTAS)

- Exame oftalmológico realizado na escola......

- Treinamento dado por pessoal não-médico

- Ampliação do tempo para realização da campanha

- Exame oftalmológico realizado no posto de saúde

- Aplicação do teste de acuidade visual por profissional da área de saúde

- Antecipação do início das atividades da campanha

19) Na sua opinião, a campanha para identificar e tratar problemas visuais de escolares realizada na escola é:

- Muito importante

- Medianamente importante

- Pouco importante

- Nada importante

- Não tenho opinião....

\section{REFERÊNCIAS}

1. Kara-José N, Carvalho KMM, Caldato R, Pereira VL, Oliveira AM, Fonseca Neto JC. Atendimento de amblíopes e prevalência na população pré-escolar, Campinas, São Paulo, Brasil. Bol Oficina Sanit Panam 1984;96:31-7.

2. Thylefors B, Négrel AD, Parajasegaran R, Dadzie KY. Global data on blindness. Bull Word Health Organ 1995;73:115-21.

3. Kara-José N, Almeida GV, Arieta CE, Araújo JS, Bechara SJ, Oliveira PR. Causas de defici6encia visual em crianças. Bol Oficina Sanit Panam 1980;97: 405-12

4. Temporini ER. Aspectos do plano de oftalmologia sanitária escolar do estado e São Paulo. Rev Saúde Pública 1982;16:243-60.

5. Burns MJ. Building a priority for national vision health care. Eye Ear Nose Throat Mon 1973,52:353-6.

6. Michaels D. Indications for prescribing spectacles. Surv Ophthalmol 1981;26: 55-74.

7. Newman DK, Hitchcock A, McCarthy H, Keast-Butler J, Moore AT. Preschool vision screening:outcome of children referred to the hospital eye service. Br J Opthalmol 1996;80:1077-82.

8. Vital-Durand F, Ayzac L. Tackling amblyopia in human infants. Eye 1996;10(Pt 2):239-44.
9. Gasparetto MERF. A criança com baixa visão e o desempenho escolar: caracterização do uso do resíduo visual [tese]. Campinas: Universidade Estadual de Campinas; 1997.

10. Oliveira RCS, Kara-José N, Arieta CEL. Manual da boa visão do escolar. São Paulo: Imprensa Oficial do Estado; 2000

11. Attebo K, Mitchell P, Cumming R, Smith W, Jolly N, Sparkes R. Prevalence and causes of amblyopia in an adult population. Ophthalmology 1998;105: 154-9.

12. Limburg H, Vaidyanathan K, Dalal HP. Cost-effective screening of schoolchildren for refractive errors. World Health Forum 1995;16:173-8.

13. Lennerstrand G, Jakobsson P, Kvarnstrom G. Screening for ocular dysfunction in children: approaching a common program. Acta Ophthalmol Scand 1995 Suppl 214:26-38, discussion p.39-40.

14. Simons K. Preschool vision screening: rationale methodology and outcome. Surv Ophthalmol 1996;41:3-30.

15. Preslan NW, Novak A. Baltimore Vision Screening Project-Phase 2. Ophthalmology 1996;105:150-3.

16. Preslan NW, Novak A. Baltimore Vision Screening Project. Ophthalmol, 1998;103:105-9.

17. World Health Organization. Strategies for the preventions of blindness in national programs - a primary health care approach. Geneva: WHO;1984.

18. Alves MR, Kara-José N. Manual de Orientação ao professor. Campanha Nacional de Reabilitação Visual Olho no Olho. São Paulo: CBO; 2000. p.40. 
19. Wasserman RC, Croft CA, Brotherton SE. Preschool vision screening in pediatric practice: a study from the pediatric research in office settings (PROS) Network. American Academy of Pediatrics. Pediatrics 1992;89(5 Pt 1):834-8.

20. Temporini ER, Kara-José N, Taiar A. Validade da aferição da acuidade visual realizada pelo professor em escolares de $1^{\mathrm{a}}$ a $4^{\mathrm{a}}$ série do primeiro grau de uma escola pública do município de São Paulo, Brasil. Rev Saúde Pública 1997; 11:229-37.

21. Macchiaverni N, Kara-José N, Rueda G. Levantamento oftalmológico em escolares da primeira a quarta séries do primeiro grau na cidade de Paulínia, São Paulo. Arq Bras Oftalmol 1979;42:289-94.

22. Kara-José N, Temporini ER. Avaliação dos critérios de triagem visual de escolares de primeira série do primeiro grau. Rev Saúde Publica 1980;14:205-14.

23. Newman DK, East MM. Prevalence of amblyopia among defaulters of preschool vision screening. Ophthalmic Epidemiol 2000;7:67-71.
24. Ingram RM, Holland WW, Walker C, Wilson JM, Arnold PE, Dally S Screening for visual defects in preschool children.Br J Ophthalmol 1986;70: 16-21.

25. Elston J. Preschool visual screening [commented on Br J Ophthalmol 1995; 79:1068-73]. Br J Ophthalmol 1995,79;1063-5.

26. Williamson TH, Andrews R, Dutton GN, Murray G, Graham N. Assessment of an inner city visual screening programme for preschool children [commented on Br J Ophthalmol 1995;79:1063-4]. Br J Ophthalmol 1995;79:1068-73.

27. Ciner EB, Dobson V, Schmidt PP, Allen D, Cyert L, Maguire M, et al. A survey of vision screening policy of preschool children in the United States. Surv Opthalmol 1999;43:445-57.

28. Temporini ER. Percepção de professores do sistema de ensino do Estado de São Paulo sobre seu preparo em saúde do escolar. Rev Saúde Pública 1988; 22:411-21.

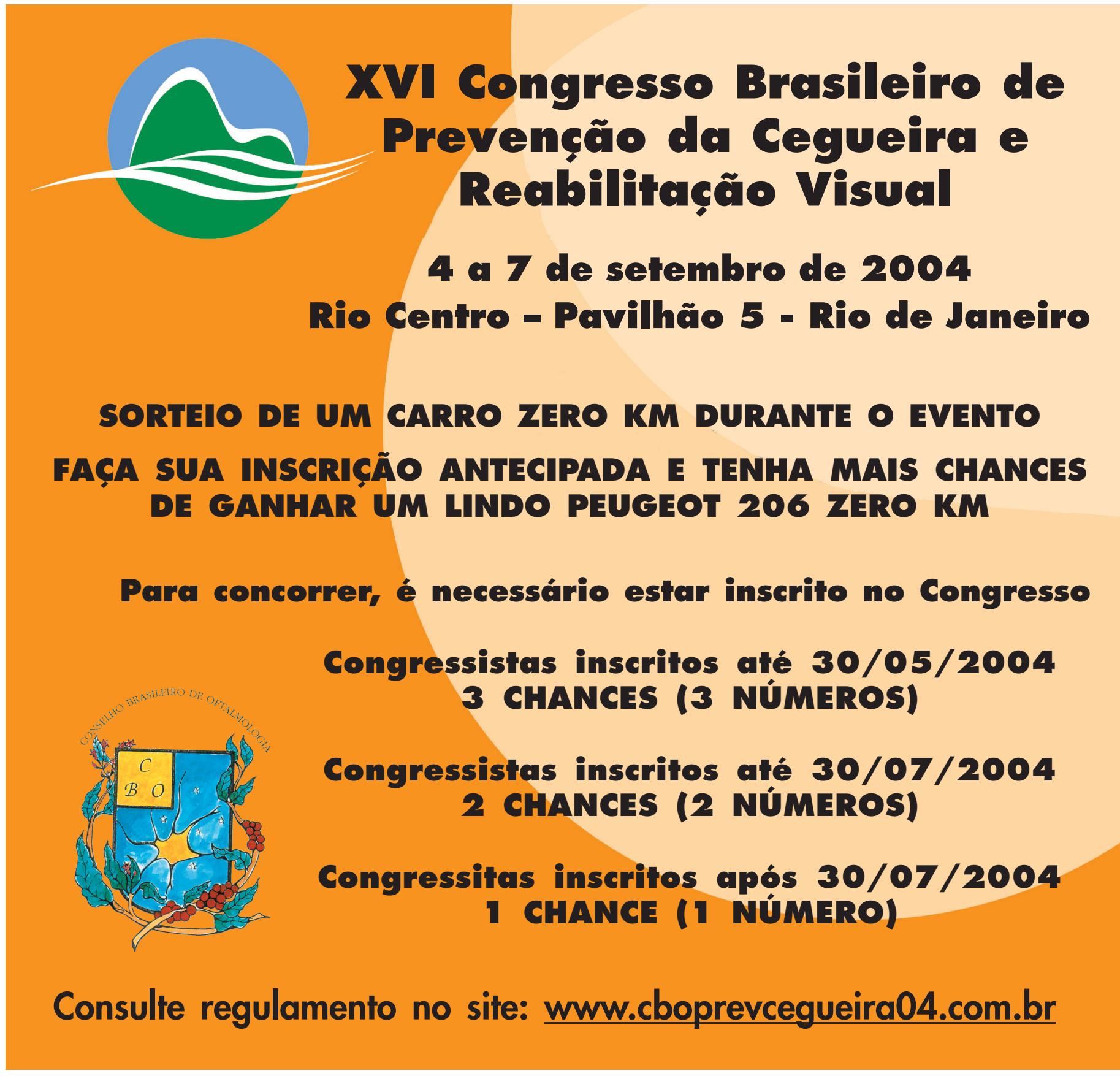

